\title{
2.2 Simplicity versus Efficiency in Sampling Designs and Estimation
}

Hans T. Schreuder

\begin{abstract}
Simplicity and efficiency in design and estimation are all important in deciding on sampling strategies A simple model is given and illustrated for four practical situations to show how an "optimal" sampling strategy should be selected.
\end{abstract}

\subsubsection{Introduction}

Traditionally, forest inventories have been planned to estimate forest parameters for certain areas at a given time, and when repeated periodically, to estimate change over time. Emphasis in the past has been on commercially important products such as total timber volume in an area. This emphasis has led to sampling designs that are highly efficient for parameters such as total volume but complex in terms of probabilities and joint probabilities of selection for certain sample units. Such designs may not be efficient in estimating change over time, since, for example, tree growth in basal area is not always positively correlated with volume or basal area. Furthermore, such designs were never intended to be the source of data for documenting possible cause-effect relationships in forest health.

Experiments are critical to document cause-effect, but they are also costly and time consuming. The political will may not exist to establish the large-scale experiments required, especially without substantial evidence that there is a problem. For example, who would have been willing to fund experiments for 20 years to establish the smoking-cancer link or the asbestos-lung cancer link without the evidence of observational studies?

The important papers by BECHTOLD et al. (1991) and RUARK et al. (1991) show how difficult it is to use forest survey data to document change in forest parameters. SCHREUDER and THOMAS (1991) contend that the use of survey data for establishing cause-effect relationships is controversial because of the lack of control over variables that may be important and particularly because true effects may be swamped by apparent effects in large, heterogeneous populations. For example, if one assumes linear models as in BECHTOLD et al. (1991), RUARK et al. (1991), and OUYANG et al. (1992) there is a good possibility that there was a significant decline in tree growth from one cycle to the next. But are linear models correct and for what populations specifically are we making the inferences? The data sets used in these papers were limited to stands that were classified as timberland at both initial and terminal inventory, were not disturbed, etc. The use of survey data to identify possible cause-effect relationships is more straightforward than actually establishing cause-effect.

SCHREUDER and CZAPLEWSKI (1992) note that broad-scale survey planning should accomplish three objectives: generate descriptive statistics, detect changes in such statistics over time, and allow for simple analytical inferences that can identify, and in some cases even establish, cause-effect relationships. Another objective that is critical due to the political climate in the U.S. and Europe is that the results should be scientifically defensible and more timely. An annual forest inventory system pilot study (AFIS 1993) may show there are opportunities to generate frequent estimates (probably on a four year 
cycle) using surveys where part of the plots are measured annually. And by flagging interesting changes occurring in the forests quickly we may be able to explain such changes more readily (there is an analogy with epidemiological studies that require fast follow-up as noted in SCHREUDER and THOMAS 1991).

Sampling strategies encompass both sample selection (design) and estimation. Estimation encompasses both generating estimates for the finite population from which the sample was selected and analytical uses of the data generated for infinite populations of which the finite population is itself a sample.

\subsubsection{Review of Literature}

SCOTT and KÖHL (1993) note that an optimal sampling design should be both efficient and simple, where simple here refers to ease of comprehension and implementation. For example, it is easier to locate a grid of sample plots on the ground then to select and establish plots proportional to their estimated volume (say from photos); it is easier to explain the Horvitz-Thompson estimator $\left(\hat{\mathrm{Y}}_{\mathrm{HT}}=\sum \mathrm{y}_{\mathrm{i}} / \pi_{\mathrm{i}}\right.$ where $\mathrm{y}_{\mathrm{i}}=$ value of interest on unit $\mathrm{i}$ and $\pi_{\mathrm{i}}=$ probability of selecting unit i) to derive a sample mean or total for simple random sampling (SRS) then for probability proportional to size (pps) sampling; and additivity of estimates is considered almost mandatory by the U.S. for Forest Inventory and Analysis (FIA) because of the difficulty of explaining numbers that don't add up. With simple designs, standard statistical software is more readily available, verification of the reliability of the programs is straightforward, and special analyses and migration to other computers are easier to do. However, the efficiency of large-scale or very expensive surveys may outweigh these advantages.

By efficiency we mean better utilization of the sampling effort to obtain results. Examples include selecting trees by variable radius plot (VRP) sampling if we are interested in volume so that more sampling effort goes into the larger and more variable trees; stratification using aerial photos or Landsat imagery to ensure that we put more sampling effort into the strata of more interest; sampling with partial replacement to ensure that there is a good balance between estimating change (for which complete remeasurement would be best); estimating current conditions (for which a large percentage of new plots is desirable); new estimation for current supplies using regression estimators instead of simple means; and purposive sampling for a simple decision.

Often the net result of this emphasis on efficiency is that although we may improve the results needed to meet certain objectives, the sampling strategy becomes more inflexible or useless for other purposes. For example, VRP sampling is great for estimating volume but it is less efficient for estimating volume growth and is more difficult to deal with than fixed-area plots when we are interested in building models or studying the effects of silvicultural or other treatments on forest growth. Efficiency in estimation due to sample selection certainly becomes a moot issue when we have many different objectives. Proportional allocation of sample units to strata (SWINDEL and YANDLE 1972) is usually optimal in such situations.

What are the advantages of efficiency in sample design and estimation? Clearly efficiency has played a highly significant role in surveys such as those conducted by FIA units of the USDA Forest Service (BIRDSEY and SCHREUDER 1992) and similar largescale surveys. We attribute this partly to an obsession with a specific parameter of interest (total volume of trees by species classes). Certainly the basic design that resulted, double sampling for stratification where trees on plots are selected by VRP sampling is efficient 
for volume estimation but not efficient for estimating number of trees or change in volume over time. A big advantage of VRP sampling compared to fixed-area plot sampling is that fewer small trees are selected in the field compared to a fixed-area plot design, so that data collection is efficient for volume. However, if an estimate of mortality is desired, it can be a disadvantage since smaller trees are more prone to die.

With the advent of the Forest and Rangeland Renewable Resources Planning Act of 1974, amended subsequently by the National Forest Management Act of 1976, attempts were made by FIA to collect multiresource information rather than timber information only. One such attempt, the "Alaska Integrated Resource Inventory System" (AIRIS) (LABAU and SCHREUDER 1983) used a simple grid of plots distributed over the population of interest: it was considered that optimizing plot selection for specific parameters was undesirable owing to the multitude of parameters being estimated. This approach also had undesirable features because it caused an inadequate sample size in river basins which support sparse forest. At that time precision levels were required for certain timber statistics only and these were not met in the basins. Clearly, stratification within the basins would have been desirable to ensure an adequate sample size in the forested areas.

What about simplicity vs. efficiency in estimation? A firm rule in FIA is that the estimates be additive, i.e., the volume of hardwoods and of softwoods should add to give the total volume of wood. Although this seems a sensible rule, it causes a loss in efficiency (e.g., WILLIAMS and SCHREUDER 1994) and makes it more difficult to obtain estimates of precision (SCHREUDER et al. 1988; and LI et al. 1990).

\subsubsection{The Concept of Desirable Objectives}

Traditionally, statisticians have asked that objectives be clearly specified in surveys. They have often deplored the lack of clarity of objectives of people doing surveys and are critical of the not uncommon attitude that "it would be nice to know although we are not quite clear what we are going to do with the data." There is considerable merit specifying clear objectives. Often when objectives can be specified very clearly, they are quite limited and complex sample selection methods that can be quite efficient should be used. For example, if the only one is to sample for total volume in a tract of land, methods such as point-Poisson sampling (GROSENBAUGH 1971), point-pps sampling (SCHREUDER et al. 1993), and modified point-list sampling (WOOD and WIANT 1992) can be very costeffective and efficient. And there are numerous examples of people wasting $\$ 50,000-$ $\$ 100,000$ on surveys with very nebulous objectives resulting in essentially worthless information. But not all desirable objectives need to be clearly specified. The following classes of objectives are proposed.

1. Clearly defined and usable information. This is almost always the justification of surveys and hence a considerable part of survey planning should be devoted to it. For example, FIA has the responsibility of estimating for each state in the U.S. the total forest acreage, total growing stock (volume), and its growth within specified precision limits.

2. Clearly defined and potentially usable information. This information should be collected if feasible, even though one may not be concerned about meeting certain precision standards. Examples of such information are percentage of forest condition classes occurring together, length of boundaries between the condition classes, and areas 
of the classes and the transition zones between them. Some condition classes are welldefined (plantations, natural hardwood and conifer stands, etc.) so that for these classes the parameters mentioned can be estimated objectively with mapped designs like those used for monitoring forest health (FHM) and in FIA surveys (WILLIAMS and SCHREUDER 1994). Survey samplers should be alert to see the opportunity for collecting information useful for user groups such as ecologists, hydrologists, wildlife specialists, etc.

3. Ill-defined but potentially usable information. Generally such information should not be collected unless political pressures are too great. Examples are ocular estimates of needle loss and vegetation profiles. Both of these features are important ecological and forest health parameters but until the corresponding variables can be measured objectively, the chances of obtaining essentially worthless information are excessive.

\subsubsection{A Decision Model: Efficiency vs. Simplicity}

Both efficiency and simplicity are a function of the number and type of objectives to be satisfied, money available for the survey, quality of information desired, need for understanding by user groups, and tightness of precision requirements. Can we develop a simple decision model to illustrate the desirability of efficiency vs. simplicity?

The concept of a decision model to decide what sampling strategy to use is desirable and is a more realistic decision tool than an approach focusing on the comparison of the efficiency of various sampling strategies. The latter approach is more useful as a teaching tool in the manner of ARVANITIS and REICH (1989) and BRINK and SCHREUDER (1992). But quantifying the relevant factors is difficult. A simple model is proposed where each variable is classified into only one of two categories. (Ultimately a computer model such as Classification and Regression Trees (CART) (BREIMAN et al. 1984, CZAPLEWSKI and KASTNER 1986) could be helpful in making the decision on what sampling strategy to use.) The basic assumption is that only two or three sampling designs and similarly estimators are considered. Having a key that automatically leads to one specific design out of the many available in the literature seems unrealistic. The basic model then for an optimal sampling strategy (OSS) is

OSS $=w_{1} n_{o}+w_{2} t_{o}+w_{3} u_{u}+w_{4} s_{d}+w_{5} n_{c}+w_{6} n_{r}+w_{7} p_{d}$

where

$\mathrm{n}_{\mathrm{o}}$ = number of objectives (many, few).

$\mathrm{t}_{\mathrm{o}} \quad=$ type of objectives (broad, narrow).

$\mathrm{u}_{\mathrm{u}}=$ user group understanding (critical, not critical).

$\mathrm{s}_{\mathrm{d}}=$ scientific defensibility (yes, no).

$\mathrm{n}_{\mathrm{c}}=$ need for continuity (critical, not critical).

$\mathrm{n}_{\mathrm{r}} \quad=$ need for renewal, i.e., start from the beginning (critical, not critical).

$\mathrm{P}_{\mathrm{d}}=$ politically defensible (yes, no).

For simplicity, set all $w_{i}$ to 1 (always for our examples) and variables to 1 if the variable is rated high (many, critical, yes), and to 0 if the indicated variable is rated low (i.e., few, not critical, no). 
These variables in some sense are expressions of simplicity and efficiency, i.e. design simplicity is

$$
\begin{aligned}
& \text { ds }=\mathrm{n}_{\mathrm{o}}+\mathrm{t}_{\mathrm{o}}+\mathrm{u}_{\mathrm{u}}+\mathrm{n}_{\mathrm{c}} \\
& \text { design efficiency is } \\
& \text { de }=\mathrm{ds}_{\text {if }} \mathrm{n}_{\mathrm{o}} \text { or } \mathrm{t}_{\mathrm{o}} \text { is large } \\
& \quad=\mathrm{u}_{\mathrm{u}}+\mathrm{s}_{\mathrm{d}} \text { otherwise; } \\
& \text { estimation simplicity is } \\
& \text { es }=\mathrm{n}_{\mathrm{c}}+\mathrm{p}_{\mathrm{d}} \\
& \text { estimation efficiency is } \\
& \text { ee }=\mathrm{n}_{\mathrm{o}}+\mathrm{u}_{\mathrm{u}}+\mathrm{s}_{\mathrm{d}} .
\end{aligned}
$$

Small and large values of ds, de, es, and ee indicate that they are relatively unimportant and important respectively. We rewrite OSS as:

OSS $=\mathrm{ds}+\mathrm{de}+\mathrm{es}+\mathrm{ee}$.

\subsubsection{Examples}

To illustrate the points made above, four hypothetical but practical situations are addressed in order of increasing complexity:

1. Sampling grizzly bears for diet in Yellowstone National Park (forestry analogue of the Basu (1971, p. 212) elephant example). Sampling alternatives considered are a simple probabilistic sampling scheme and purposive sampling.

Yellowstone National Park has 25 grizzly bears on the loose. Visitors do not take too kindly to being mauled by them and the National Park Service does not take kindly to either that or funding a major study to determine the meat requirements of the bears. Only one bear can be studied to determine its requirements in order to estimate total meat consumption. If the bears get enough meat, mauling may be kept to a minimum. So we want to estimate $\mathrm{Y}=\sum_{i=1}^{25} \mathrm{y}_{\mathrm{i}}$ where $\mathrm{y}_{\mathrm{i}}=$ meat requirement of bear $\mathrm{i}$. How do we pick our bear? Sue Love, wildlifer extraordinaire, has studied these bears for three years and offers us probabilities of the bears being representative. She is convinced that bear 13 is typical whereas she thinks that bear 1 eats only $1 / 2$ of the meat that the average bear eats and bear 25 is a true hog (i.e. eats as much as the 24 others combined). Basically she offers us the following recommended probabilities of selection $(p)$.

$$
\begin{aligned}
& \text { Bear }
\end{aligned}
$$

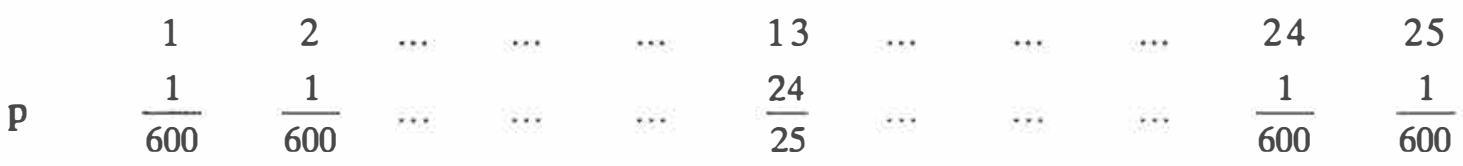

What bear do we select for the study? We only consider two options: Deliberate selection of one bear and multiplying his meat intake by 25 (strategy D) or selecting a bear by the probabilities given to us by Sue Love and using the Horvitz-Thompson estimator (strategy P). In this situation $n_{o}=t_{o}=n_{c}=n_{r}=0$ and $u_{u}=$ critical. $s_{d}$ and $p_{d}$ can be argued about but as the decision maker, we set $s_{d}=0$ and $p_{d}=1$ and obtain: 


$$
\begin{aligned}
\text { ds } & =u_{u} \\
\text { de } & =u_{u} \\
e s & =p_{d} \\
e e & =u_{u}
\end{aligned}
$$

From this it is clear that the sampling strategy needs to be understood by the user group and should be politically defensible. One wants to maximize OSS $=3 u_{u}+p_{d}$. This means that the deliberate selection of bear 13 and multiplying his meat intake by 25 would be the preferred option. Hence heavy emphasis is placed on $u_{u}$ and less on $p_{d}$ and both are maximized more by $\mathrm{D}$ than P. Although the chances of selecting bear 1 or 25 would be slight, they are positive and if we trust Sue Love at all I would not want to defend $\hat{\mathrm{Y}}_{\mathrm{HT}}$ (or the simple average times 25 either, for that matter) if these bears were selected.

2. Timber sale. Interest is in estimating total timber volume on a 200 ha clearcut area so that potential buyers can bid on it.

The options to consider are the selection of 10 plots by either fixed-area plot sampling or VRP sampling using $\hat{\mathrm{Y}}_{\mathrm{HT}}$. In this situation, $\mathrm{n}_{\mathrm{o}}=\mathrm{t}_{\mathrm{o}}=\mathrm{n}_{\mathrm{c}}=\mathrm{n}_{\mathrm{r}}=0$ so that we have

$$
\begin{aligned}
\text { ds } & =u_{u} \\
\text { de } & =u_{u}+s_{d} \\
\text { es } & =p_{d} \\
\text { ee } & =u_{u}+s_{d}
\end{aligned}
$$

so we want to maximize

$$
\text { OSS }=3 u_{u}+2 s_{d}+p_{d} \text {. }
$$

Given the sampling strategy options, $\mathrm{u}_{\mathrm{u}}$ and $\mathrm{p}_{\mathrm{d}}$ would be optimized by the VRP sampling strategy and $s_{d}$ would be equal for both approaches. Note that some 30 years ago one could have argued that fixed-area plot sampling would be preferred because user understanding of VRP sampling would have been essentially non-existent.

3. Maintain the current FIA design with VRP cluster ground sampling or use fixed-area cluster plots as in the forest health monitoring (FHM) design used by the U.S. Forest Service. $\hat{\mathrm{Y}}_{\mathrm{HT}}$ is used for both with all parameters.

Here all variables are important except that $\mathrm{n}_{\mathrm{r}}=0$ may be reasonable. So we obtain OSS $=3 \mathrm{n}_{\mathrm{o}}+2 \mathrm{t}_{\mathrm{o}}+3 \mathrm{u}_{\mathrm{u}}+2 \mathrm{~s}_{\mathrm{d}}+2 \mathrm{n}_{\mathrm{c}}+2 \mathrm{n}_{\mathrm{r}}+3 \mathrm{p}_{\mathrm{d}}$

This is not an obvious situation. $\mathrm{n}_{\mathrm{o}}, \mathrm{t}_{\mathrm{o}}, \mathrm{n}_{\mathrm{r}}$ and $\mathrm{u}_{\mathrm{u}}$ are maximized with the fixed-area plot design but $n_{c}$ is maximized with the VRP design, and $p_{d}$ would be about the same for both approaches. Heavy emphasis is placed on $n_{c}$ in FIA so several FIA project leaders favor VRP sampling but certainly some of them and others would argue in favor of fixed-area plot sampling. 
4. Redesign and merge the FIA and FHM designs to meet a multitude of objectives (see Schreuder and Czaplewski 1992).

The distinction between this situation and the earlier one in \#3 is that now

OSS $=3 \mathrm{n}_{\mathrm{o}}+2 \mathrm{t}_{\mathrm{o}}+3 \mathrm{u}_{\mathrm{u}}+2 \mathrm{~s}_{\mathrm{d}}+2 \mathrm{n}_{\mathrm{r}}+3 \mathrm{p}_{\mathrm{d}}$.

None of the variables are maximized by VRP sampling and the decision to accept fixedarea plot sampling is obvious.

\subsubsection{Concluding Comments}

Simplicity and efficiency are both important considerations when selecting a sampling strategy. A simple linear model shows the important variables to be considered in such a selection. This is illustrated with four realistic sampling situations in which it is demonstrated that different sampling strategies may be selected depending on the relative value attached to the variables considered. Further work should refine the proposed approach.

\subsubsection{References}

AFIS, 1993: Problem analysis for Annual Forest Inventory System (AFIS). USDA Forest Service, NC For. Exp. Sta., St. Paul, Minnesota. Unpublished manuscript.

ARVANITIS, L.G.; REICH, R.M., 1989: Sampling simulations with a microcomputer. Coenoses 4: 73-80.

BASU, D., 1971: An essay on the logical foundations of survey sampling, Part 1. In: GODAMBE, V.P.; SPROTT, D.A. (eds.): Foundations of Statistical Inference. Holt, Rinehart, and Winston, NY, 203-242 (includes discussion).

BECHTOLD, W.A.; RUARK, G.A.; LLOYD, F.T., 1991: Changing stand structure and regional growth reductions in Georgia's natural pine stands. For. sci. 37: 703-717.

BIRDSEY, R.A.; SCHREUDER, H.T., 1992: An overview of forest inventory and analysis estimation procedures in the eastern U.S. - with an emphasis on components of change. USDA Forest Service, RM Techn. Rep. RM-214. 11 pp.

BREIMAN, L.; FRIEDMAN, J.A.; OSHEN, R.A.; STONE, C.J., 1984: Classification and Regression Trees. Wadsworth Intern. Group, Wadsworth, Inc., Belmont, CA. 358 pp.

BRINK, G.B.; SCHREUDER, H.T., 1992: Onephase: a simulation program to compare 1-phase sampling strategies. USDA Forest Service, RM For. and Range Exp. Stat. Res. Pap. RM-302. 8 pp.

CZAPLEWSKI, R.; KASTNER, W., 1986: Developing a dichotomous photointerpretation key using ancillary photo-data and a numerical distribution-free classifier. Proc. Use of Auxiliary Information in Natural Resource Inventories. Oct. 1-2, 1985, Blacksburg, VA. Soc. Amer. For. Publ. No. SAF 86-01: 124-134.

GROSENBAUGH, L.R., 1971: STX I-II-71 for dendrometry of multistage 3P samples. USDA For. serv. Publ. FS-277. 63 pp.

LABAU, V.J.; S CHREUDER, H.T., 1983: A multi-phase multiresource inventory procedure for assessing renewable natural resources and monitoring change. Renewable Resources Inventories for Monitoring Changes and Trends. August 1983, Corvallis, Oregon. Soc. Amer. For. Publ. No. 83-14: 456-457.

LI, H.G.; SCHREUDER, H.T.; SCOTT, C.T., 1990: Combining estimates that are both in error subject to marginal constraints. Can. j. for. res. 20: 1675-1679.

OUYANG, Z.; SCHREUDER, H.T.; LI, J., 1992: A re-evaluation of the growth decline in Georgia and Georgia-Alabama. Proc. Applied Statistics in Agriculture. April 28-30, 1991, Kansas State Univ., Manhattan, KS. 54-61. 
RUARK, G.A.; THOMAS, C.E.; BECHTOLD, W.A.; M AY, D.M., 1991: Growth reductions in naturally regenerated southern pine stands in Alabama and Georgia. South. J. Appl. For. 15: 73-79.

SCHREUDER, H.T.; CZAPLEWSKI, R.L., 1992: Long-term strategy for the statistical design of a forest health monitoring system. Env. Mon. Assess. 27: 81-94.

SCHREUDER, H.T.; THOMAS, C.E., 1991: Establishing cause-effect relationships using forest survey data. For. sci. 37: 1497-1525 (includes discussion).

SCHREUDER, H.T.; GREGOIRE, T.G.; WOOD, G., 1993: Sampling Methods for Multiresource Forest Inventory. New York, John Wiley \& Sons. 446 pp.

SCHREUDER, H.T.; LI, H.G.; RYAN, M.G.; SCOTT, C.T., 1988: Adjusting estimates in two-way tables by incorporating outside information. Can. j. for. res. 18: 1280-1285.

SCOTT, C.T.; KOHL, M., 1993: A Method for Comparing Sampling Design Alternatives for Extensive Inventories. Mitt. Eidgenöss. Forsch.anst. Wald Schnee Landsch. 68, 1: 62 pp.

SWINDEL, B.F.; YANDLE, D.O., 1972: Allocation in stratified sampling as a game. J. Amer. Stat. Assoc. 67: 684-686.

WILLIAMS, M.S.; SCHREUDER, H.T., 1994: Documentation and evaluation of growth and other estimators for the mapped design used by FIA: A simulation study. Subm. to For. sci.

WOOD, G.B.; WIANT, H.V., 1992: Comparison of point-3P and modified paint-list sampling for inventory of mature native hardwood forest in southeastern New South Wales. Can. j. for. res. 22: $125-128$. 